\title{
Selection of Ground Motion Prediction Equations for the Global Earthquake Model
}

\author{
Jonathan P. Stewart, ${ }^{\text {a) }}$ M.EERI, John Douglas, ${ }^{\text {b) }}$ Mohammad Javanbarg, ${ }^{\text {c) }}$ \\ Norman A. Abrahamson, ${ }^{c)}$ M.EERI, Yousef Bozorgnia, ${ }^{c)}$ M.EERI, David M. \\ Boore, ${ }^{\text {d) }}$ Kenneth W. Campbell ${ }^{\mathrm{e})}$ M.EERI, Elise Delavaud, ${ }^{\mathrm{f})}$ Mustafa Erdik, \\ M.EERI, and Peter J. Stafford, ${ }^{\text {h) }}$ M.EERI
}

Ground-motion prediction equations (GMPEs) relate ground-motion intensity measures to variables describing earthquake source, path, and site effects. We select from many available GMPEs those models recommended for use in seismic hazard assessments in the Global Earthquake Model. We present a GMPE selection procedure that evaluates multi-dimensional ground motion trends (e.g., with respect to magnitude, distance and structural period), examines functional forms, and evaluates published quantitative tests of GMPE performance against independent data. Our recommendations include: four models, based principally on simulations, for stable continental regions (SCRs); three empirical models for interface and in-slab subduction zone (SZ) events; and three empirical models for active shallow crustal regions (ACRs). To approximately incorporate epistemic uncertainties, the selection process accounts for alternate representations of key GMPE attributes, such as the rate of distance attenuation, which are defensible from available data. Recommended models for each domain will change over time as additional GMPEs are developed.

Keywords: Engineering seismology, ground-motion prediction, site effects, Global Earthquake Model, GMPE selection, seismic hazard assessment.

\footnotetext{
a) University of California, Los Angeles, CA, USA jstewart@ seas.ucla.edu

b) BRGM, Orléans, France

c) PEER Center, University of California, Berkeley, CA USA

d) US Geological Survey, Menlo Park, CA USA

e) EQECAT, Inc., Beaverton, OR USA

f) ETH, Zurich, Switzerland

g) KOERI, Istanbul, Turkey

h) Imperial College London, UK
} 


\section{INTRODUCTION}

Ground-motion prediction equations (GMPEs) relate a ground-motion parameter (e.g., peak ground acceleration, PGA) to a set of explanatory variables describing the earthquake source, wave propagation path and local site conditions (e.g., Douglas, 2003). These independent variables invariably include magnitude, source-to-site distance and some parameterization of local site conditions, and often style-of-faulting (mechanism). Some recent models also account for other factors affecting earthquake ground motions (e.g. hanging wall effects). In the past five decades many hundreds of GMPEs for the prediction of PGA and linear elastic response spectral ordinates have been published, which are summarized in a series of public reports by the second author (e.g., Douglas, 2011). Therefore, the seismic hazard analyst is faced with the difficult task of deciding which GMPEs to use for a given project. This decision is a critical step in any hazard assessment because the resulting predicted spectra are strongly dependent on the GMPEs chosen.

We describe the selection process for GMPEs undertaken within the framework of the Global Earthquake Model (GEM) Global GMPEs project, coordinated by the Pacific Earthquake Engineering Research Center (PEER) (Di Alessandro et al., 2012). The process began by pre-selecting from available models the most robust GMPEs as candidates for final selection. This pre-selection was based on applying the exclusion criteria of Cotton et al. (2006) to the complete list of models summarized by Douglas (2011). These qualityassurance criteria exclude models that, for example: are superseded by more recent GMPEs; do not allow predictions for the entire magnitude-distance-structural period range of interest; and employ independent (e.g., magnitude scale) or dependent (e.g., horizontal component definition) parameters that would complicate their use in state-of-the-art seismic hazard assessments. As described by Douglas et al. (2012), this screening process within Task 2 of the GEM-PEER project led to the identification of roughly ten GMPEs for each of three major tectonic regimes/domains (active crustal regions, ACRs; subduction zones, SZs; stable continental regions, SCRs).

Global applications within GEM require about three to four recommended GMPEs for each major tectonic regime for practical reasons (e.g., calculation times). Ideally, the selection of those GMPEs should account for regional differences within the ACR, SZ, and SCR regimes, which takes the form of variable GMPE attributes (such as rate of distance attenuation). In this article, we describe the work undertaken in Task 3 of the GEM-PEER project to balance these competing objectives in the selection process of having few, 
relatively robust models that approximately represent epistemic uncertainty in ground-motion prediction. The process, supporting plots, and results are described in more detail in a PEER report (Stewart et al., 2013).

Previous GMPE selection tasks have been undertaken for global applications (GEM1 pilot project, Douglas et al., 2009), Europe (SHARE project, Delavaud et al., 2012), and the Middle East Region (EMME project, S. Akkar, written communication, 2012). This project is differentiated from the prior work in its global reach (which only GEM1 had previously attempted) and the approach that was developed to make the selections. In this article, we emphasize the selection process, which can have long-term applicability, even after the GMPEs that we have selected are superseded.

Subsequent sections present the procedure followed in GEM-PEER Task 3, including the composition of the expert panel and the information considered during the selection process. The next two sections describe the main tools used in the selection process, which are trellis plots that compare GMPE predictions for various earthquake scenarios, and a review of published studies quantitatively comparing predicted and observed response spectral accelerations in recent earthquakes. We then provide our recommended GMPEs for GEM global applications along with the rationale for their selection. For brevity, only a small subset of the material used by the experts to make the final selection is presented herein. A more complete, but still abridged, set of plots is provided in an Electronic Supplement, while complete plots are given in Stewart et al. (2013).

\section{SELECTION PROCEDURE AND FACTORS CONSIDERED}

In this section, we present the overall procedure developed to select GMPEs for the three principal tectonic regimes (SZs, ACRs and SCRs). The project was overseen by a core group of experts and a wider expert panel that comprised all members of the project team (Table E.1 in electronic supplement). The core group was responsible for preparing initial GMPE recommendations for the three regimes, which were then presented to the wider expert panel for discussion and potential revision.

We identified criteria for GMPE selection in SZ and ACR regimes as:

1. More emphasis given to GMPEs derived from international than from local data sets. Exceptions can be made when a GMPE derived from a local data set has been checked internationally and found to perform well. 
2. More emphasis given to GMPEs that have attributes of their functional form that we consider desirable, including saturation with magnitude, magnitude-dependent distance scaling and terms that mimic the effects anelastic attenuation.

3. If there are multiple GMPEs that are well constrained by data but exhibit different trends, it is desirable to capture those trends in the selected GMPEs to properly represent epistemic uncertainty.

For SCRs, where strong-motion data are scarce, these criteria were modified to:

1. SCR GMPEs are derived principally from the results of numerical simulations. However, the manner in which the limited available data is used to constrain the input parameters for the simulations is critical. The empirical calibration may influence, for example, stress drop parameters and site attenuation $\left(\kappa_{0}\right)$. We prefer GMPEs judged to effectively use the available data to constrain model parameters.

2. Same as criteria \#2 above (desirable attributes of functional form). Since data are limited for SCRs, it is especially important that the selected models extrapolate in a reasonable manner beyond the data range.

3. We seek GMPEs that meet the above criteria and which collectively: $(i)$ represent diverse geographic regions and (ii) use alternative simulation methodologies. This is intended to represent epistemic uncertainty in the selected GMPEs.

In the selection process, we decided not to down-weight GMPEs with difficult-toimplement parameters (e.g., basin depth terms or depth to top of rupture), because those issues can be overcome with appropriate parameter selection protocols (e.g., Kaklamanos et al., 2011). We also decided not to down-weight GMPEs that either lack site terms or whose modeling of site response is non-optimal (e.g., lack of nonlinearity) because GMPEs can be evaluated for a reference rock site condition in hazard analysis and site effects subsequently added in a hybrid process (Cramer, 2003; Goulet and Stewart, 2009).

The principal resources developed for GMPE selection were a synthesis of functional forms, plots showing comparative ground motion scaling with predictive parameters (distance, magnitude, period, site condition), and model-data comparisons from the literature. The latter two are described in the following sub-sections. In the synthesis of functional forms, we repeat the equations using consistent terminology across GMPEs (details in Stewart et al., 2013). Some models assume simple linear scaling with magnitude and $1 / R$ distance decay (where $R$ is site-to-source distance), whereas others account for more complex 
effects (e.g., magnitude-saturation and magnitude-dependent distance scaling). Such effects can be clearly seen from comparative GMPE scaling plots in the next section.

\section{COMPARATIVE GMPE SCALING (TRELLIS PLOTS)}

\section{ACTIVE CRUSTAL REGIONS (ACRs)}

Trellis charts were drawn to display the multi-dimensional (magnitude, source-to-site distance, structural period etc.) predicted ground-motion space in various ways to provide insight into the pre-selected GMPEs. The aim is to help identify outliers with clearly nonphysical behavior but also to help guide the selection of models to capture epistemic uncertainty (e.g., the distance attenuation rate appears to be regionally dependent so it is important that this variation is captured). The charts are prepared for rock site conditions and site effects are considered in separate plots.

Trellis plots for ACRs are given for pseudo-spectral acceleration (PSA) versus period in Figure 1, PSA versus magnitude (M) in Figure 2, and PSA versus distance in Figure 3. Plots of the standard deviation terms from these models are given in Figure E.1 (electronic supplement). Figure 1 shows that the predicted spectra of the nine ACR GMPEs show relatively less model-to-model variability than those from the other two tectonic regimes (shown subsequently in Figures 6 and 10). The predicted spectra from MEA06 for M 5 earthquakes are considerably higher than the others, perhaps because this magnitude is below the minimum magnitude recommended for application. This characteristic makes this GMPE less appealing since possible over-prediction of ground motions from moderate earthquakes could have a large impact on results of hazard analyses and risk assessments, particularly when short return periods are important or seismicity rates are relatively low (but still qualifying as active). Predictions from the FEA10 model often fall below the majority of models and display a different spectral shape (with two shallow peaks at longer source-to-site distances). This could be due to it being based on a limited number of records having rocklike site conditions. 


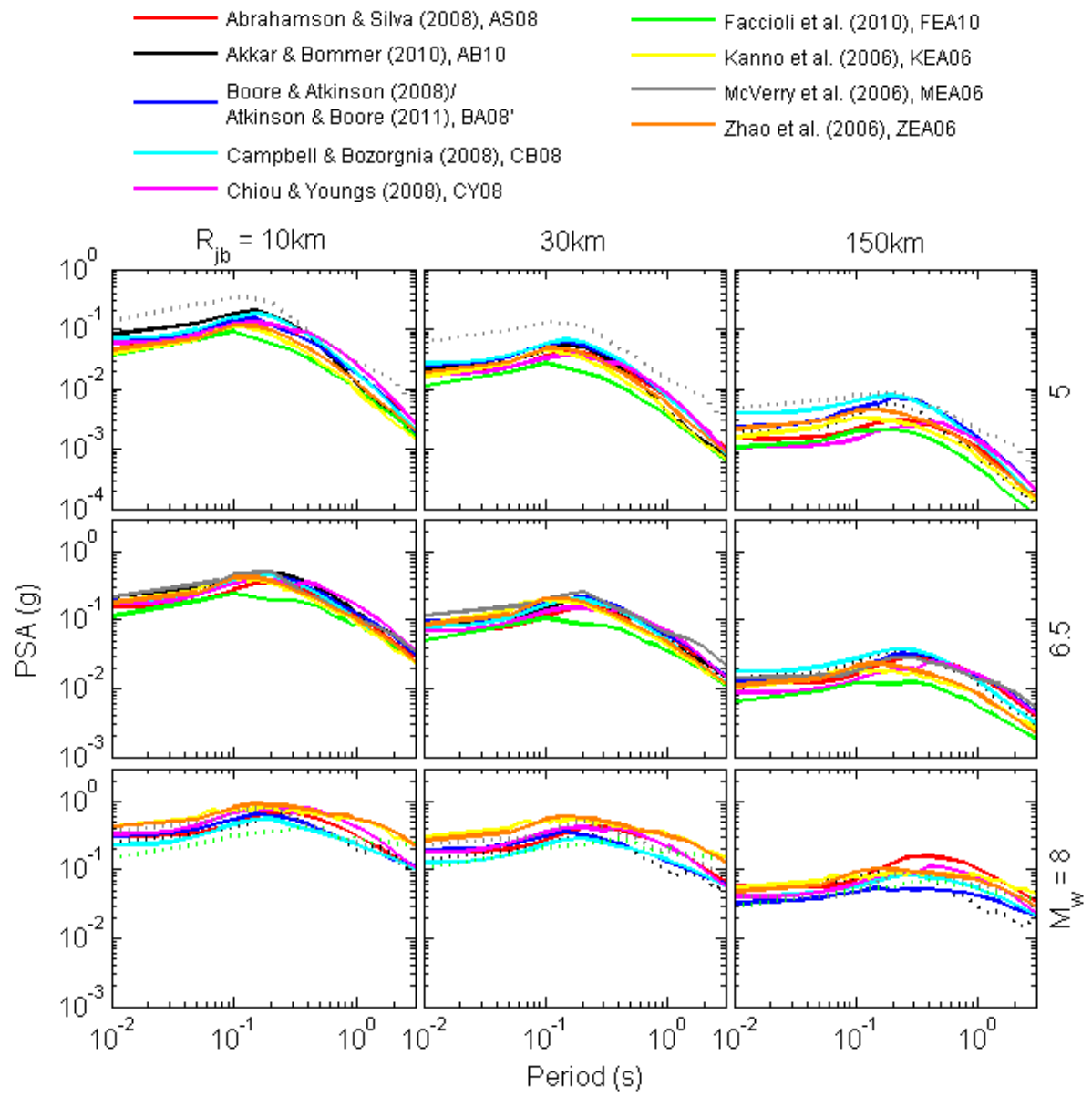

Figure 1.Trellis chart showing predicted PSAs for pre-selected ACR GMPEs for various earthquake scenarios for rock site conditions. Dashed lines indicated where the scenario falls outside the magnitude-distance range of validity of the model. The model abbreviations given in the legend are used from henceforth.

Figure 2 shows magnitude-scaling of the ACR GMPEs. The models of KEA06 and FEA10 lack magnitude saturation (i.e., PSA scales linearly with $\mathrm{M}_{\mathrm{w}}$ ), which argues against their selection since they can lead to the prediction of unphysically large or small ground motions at the edges of the magnitude-distance range of interest. Figure 3 shows the distance attenuation of the ACR GMPEs. All of the models have magnitude-dependent attenuation terms, but a point of differentiation is that some include effective anelastic attenuation leading to steeper attenuation for distances beyond 70-100 km (BA08, CY08, MEA06 and ZEA06) and some do not (AS08, AB10, CB08, FEA10 and KEA06). 


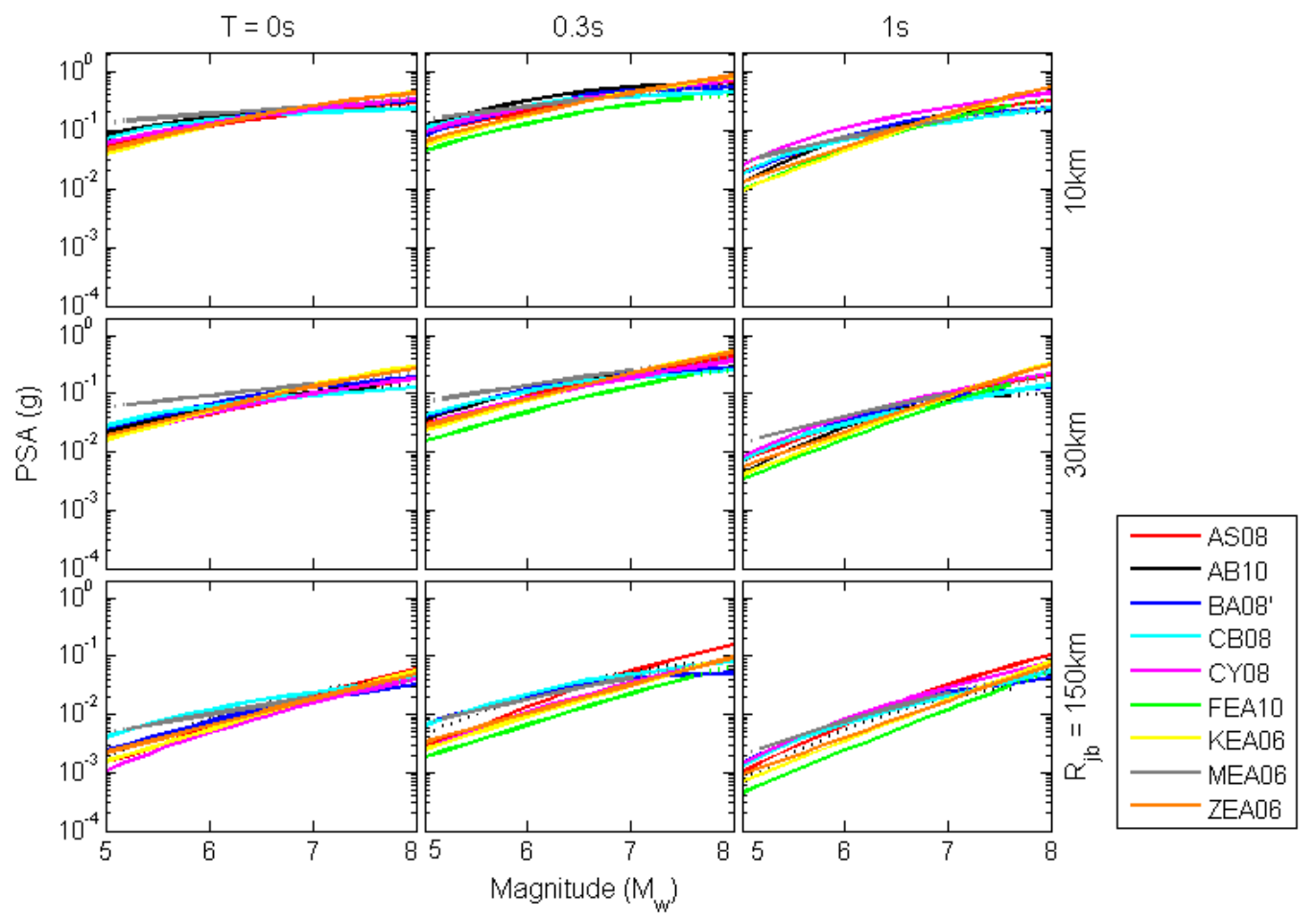

Figure 2.Trellis chart showing magnitude-scaling of predicted PSAs for pre-selected ACR GMPEs for various structural periods and source-to-site distances for rock site conditions. Dashed lines indicated where the scenario falls outside the magnitude-distance range of validity of the model.

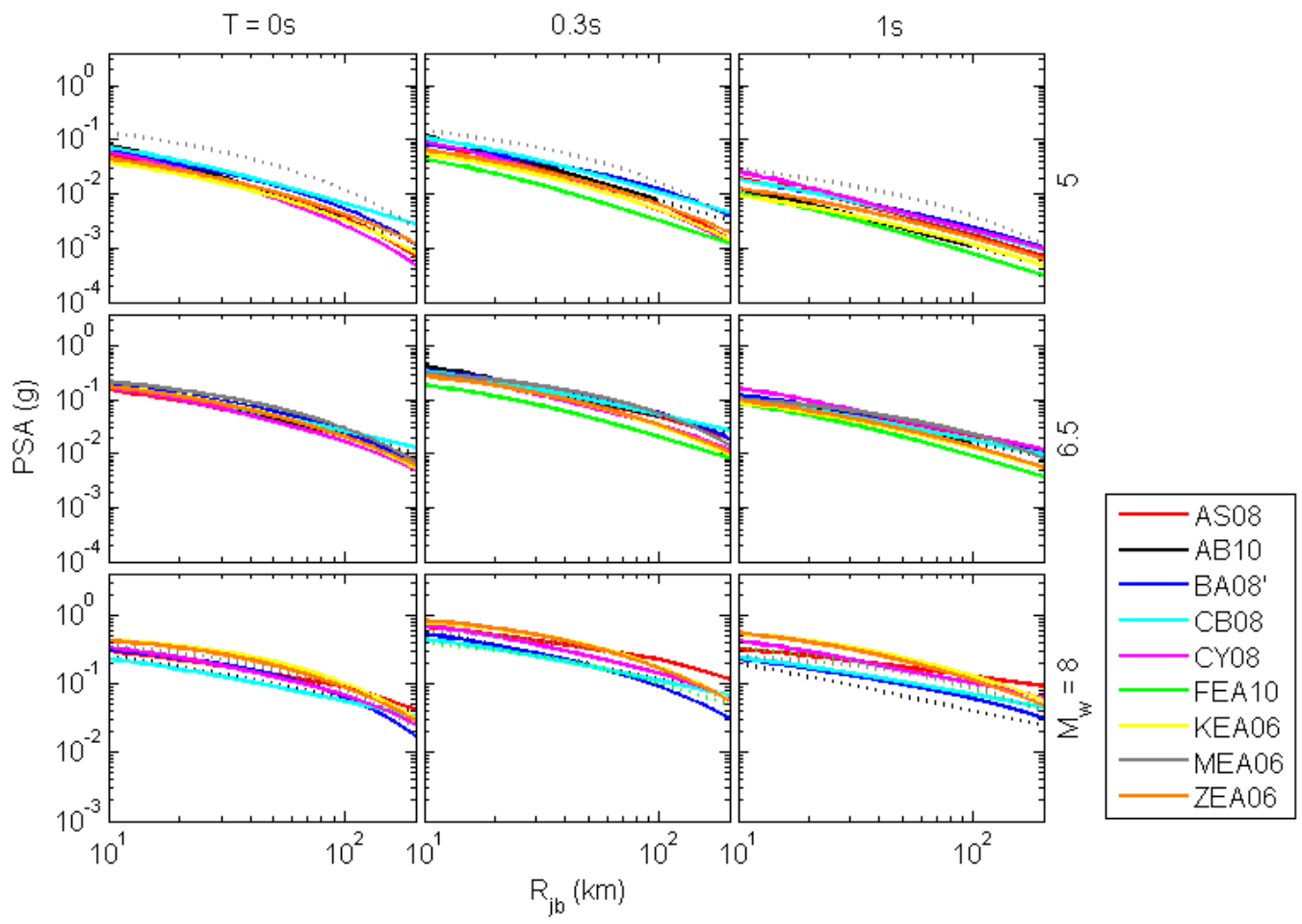

Figure 3.Trellis chart showing distance decay of predicted PSAs for pre-selected ACR GMPEs for various structural periods and magnitudes for rock site conditions. Dashed lines indicated where the scenario falls outside the magnitude-distance range of validity of the model. 
The site response functions in the ACR GMPEs are shown in Figure $4\left(V_{s 30}\right.$-scaling, where $V_{s 30}$ is the time-averaged shear wave velocity in the upper $30 \mathrm{~m}$ of a site) and Figure 5 (soil nonlinearity). Starting with $V_{s 30}$-scaling, three of the models (FEA10, KEA06, and ZEA06) are predominantly derived from Japanese data, yet have significantly different scaling at mid-to-short periods, with FEA10 and KEA06 being very strong relative to worldwide models and ZEA06 being somewhat weaker. Based on unpublished results from the NGA-West2 project, the ZEA06 trend is considered more representative for Japan. The $V_{s 30^{-}}$ scaling from international models (e.g., AS08, BA08, CB08 and CY08) at short periods is stronger, indicating a potential regional dependency in site amplification, which should be considered in selecting GMPEs for ACRs. Turning next to nonlinearity (Figure 5), the models of AB10, FEA10, KEA06, MEA06 and ZEA06 are linear whereas the others are nonlinear at short periods. A lack of nonlinearity leads to significant overestimation of ground motions for strong levels of input motions for soil site conditions and mid-to-shortperiods. For soft soil conditions, there are large differences (up to a factor of 10) in the predicted amplifications for high shaking levels, which are not considered realistic.
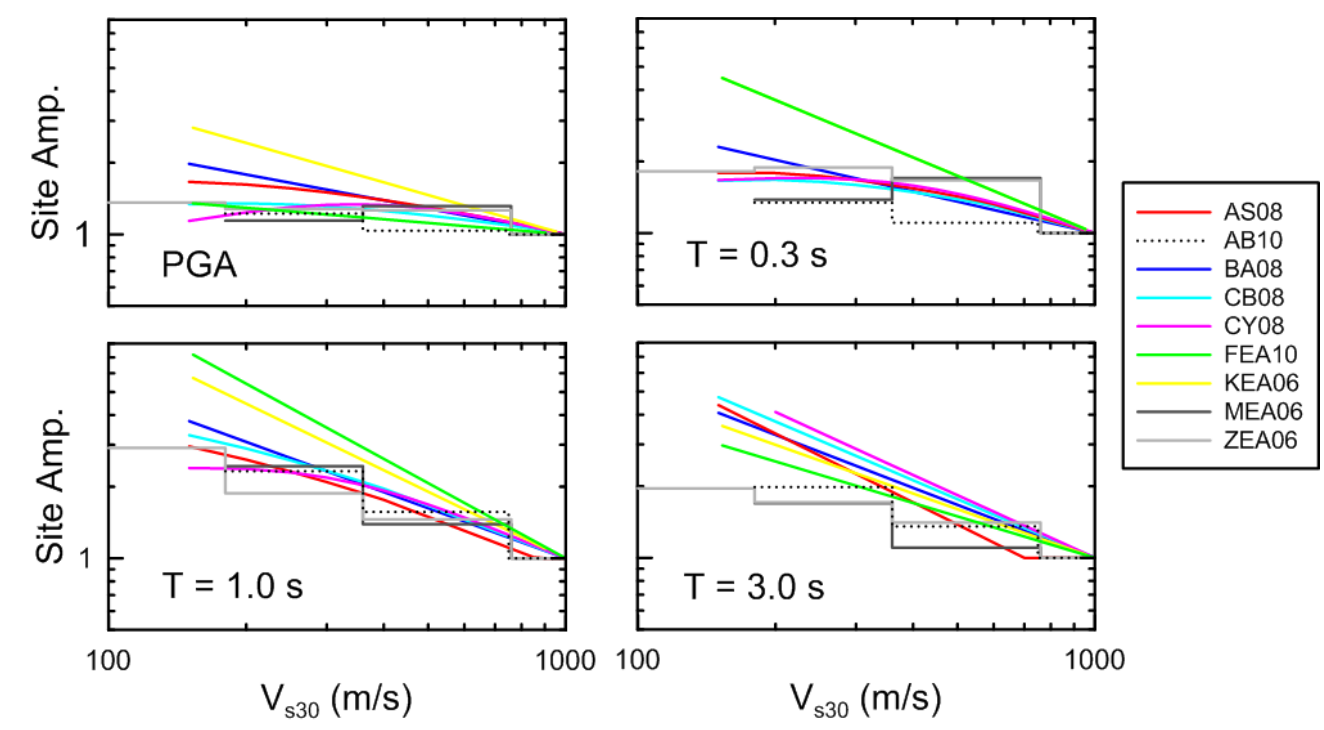

Figure 4.Trellis chart showing $V_{s 30}$-scaling of the ACR GMPEs for a reference rock peak acceleration of $\mathrm{PGA}_{\mathrm{r}}=0.1 \mathrm{~g}$. Amplification has been computed relative to a consistent reference velocity of $V_{\text {ref }}=$ $1000 \mathrm{~m} / \mathrm{s}$, regardless of the reference condition used in the GMPE. Stepped relationships (e.g., AB10) describe site response relative to discrete categories whereas continuous relations use $V_{s 30}$ directly as the site parameter. 

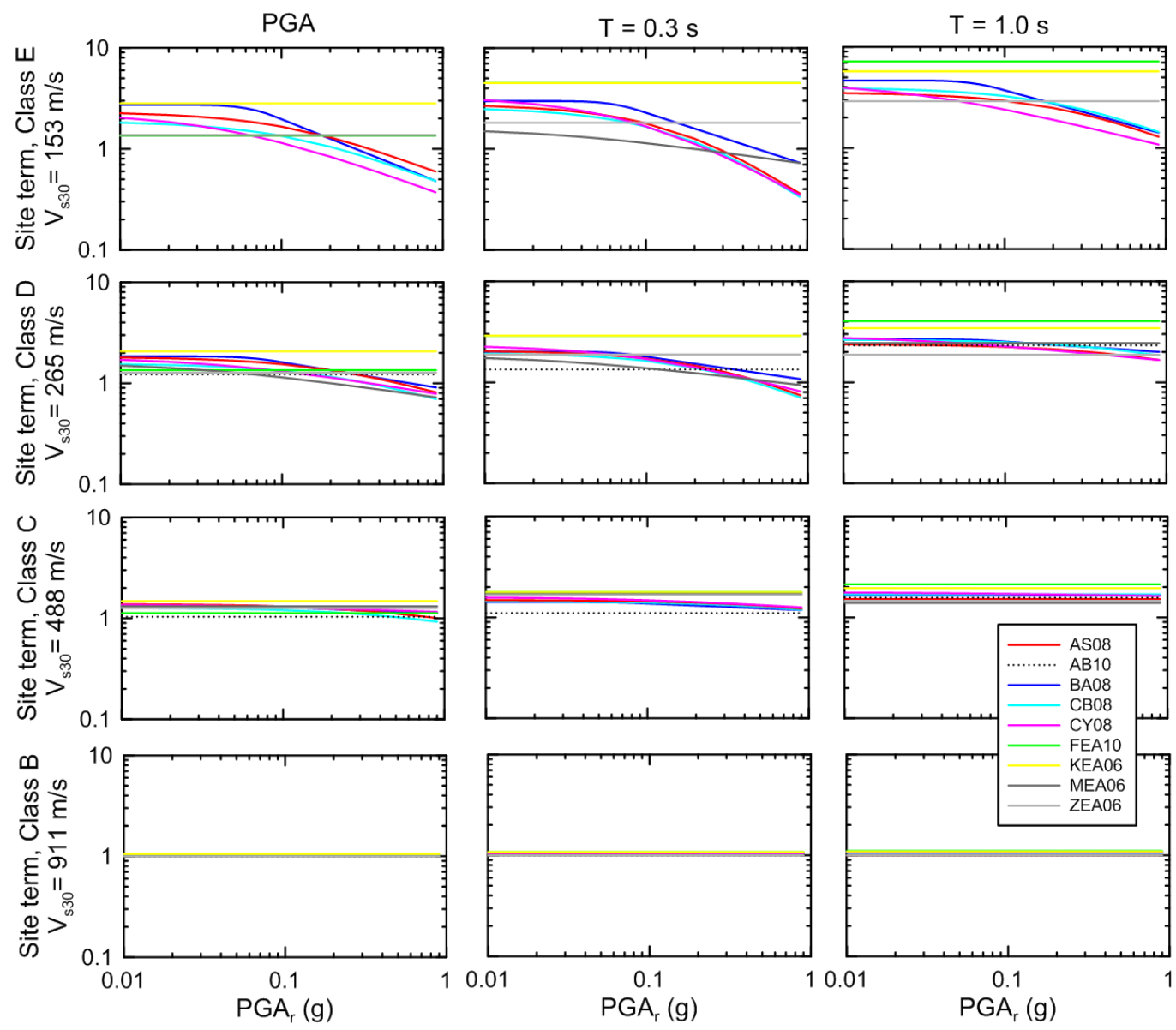

Figure 5. Trellis chart showing variation of site amplification with reference rock peak acceleration (for $V_{r e f}=1000 \mathrm{~m} / \mathrm{s}$ ) for various site classes and period. Representative velocities for each site class are based on category medians in the NGA-West2 database (Seyhan and Stewart, 2012).

\section{SUBDUCTION ZONES (SZs)}

Pre-selection criteria for SZs required that the models distinguish between interface events at the plate boundary and in-slab events. We prepared separate sets of trellis plots for both event types, but here emphasize interface events for brevity. (similar in-slab plots in Stewart et al. 2013). Interface SZ trellis plots are given for PSA against period in Figure 6, PSA versus magnitude (M) in Figure 7, and PSA with respect to distance in Figure 8. Plots of the standard deviation terms from these models are given in Figure E.2 (electronic supplement). Examining the trellis charts for the interface SZ GMPEs shows that the KEA06 model is an outlier, particularly at long periods, when evaluated for large magnitude earthquakes (Figure 6) because linear magnitude-scaling is assumed (Figure 7). This suggests that this model is not a good candidate because this behavior may lead to erroneous hazard analyses for locations where very large events are possible. Linear magnitude scaling is also used by LL08, AEA10, and AB03, but these models also have a magnitude-dependent distance decay that effectively produces nonlinear magnitude-scaling, as shown in Figure 7. 


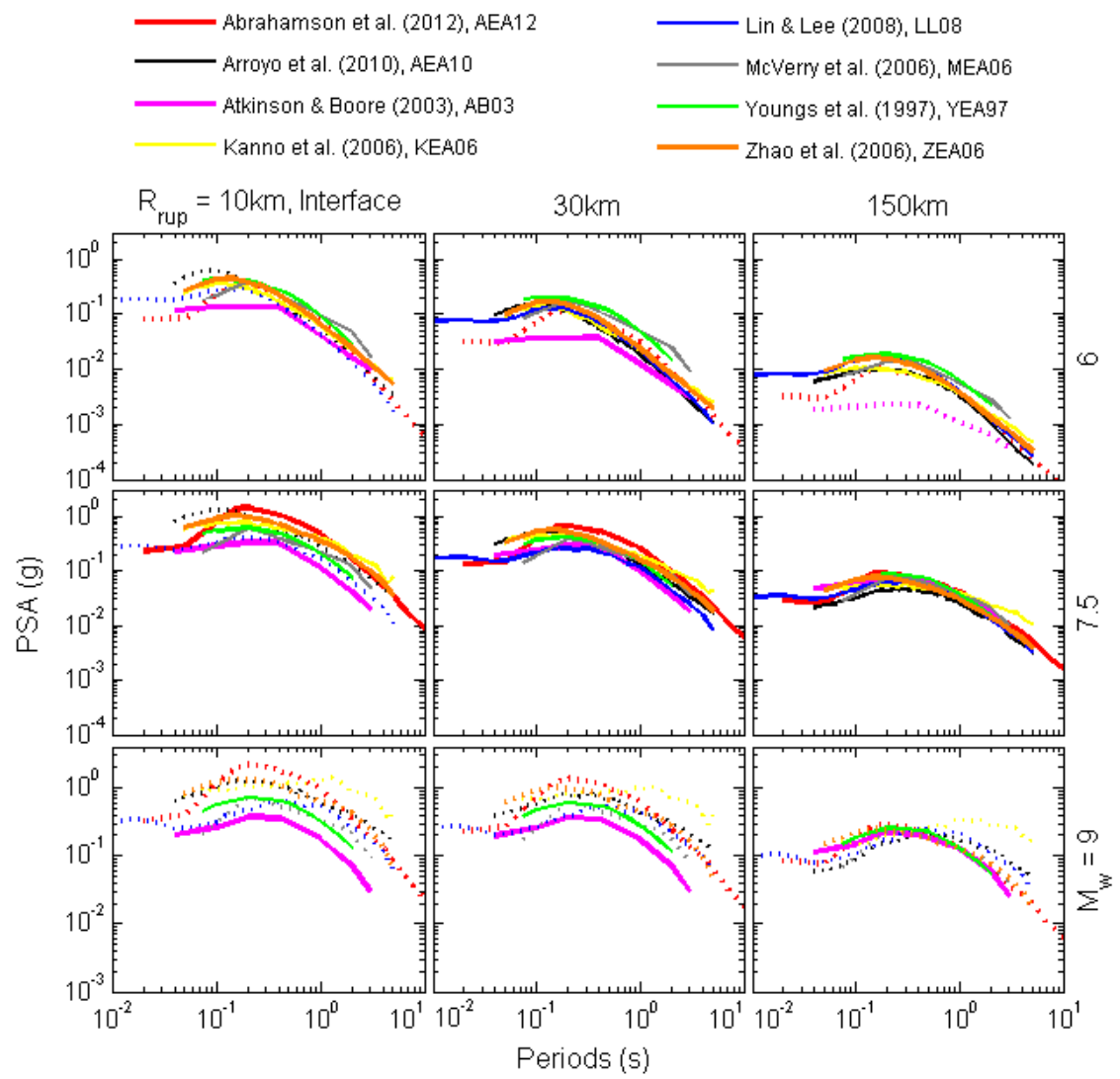

Figure 6.Trellis chart showing predicted PSAs for pre-selected SZ GMPEs for various interface earthquake scenarios for rock site conditions. Dashed lines indicated where the scenario falls outside the magnitude-distance range of validity of the model. Abbreviations for these GMPEs are defined in the legend.

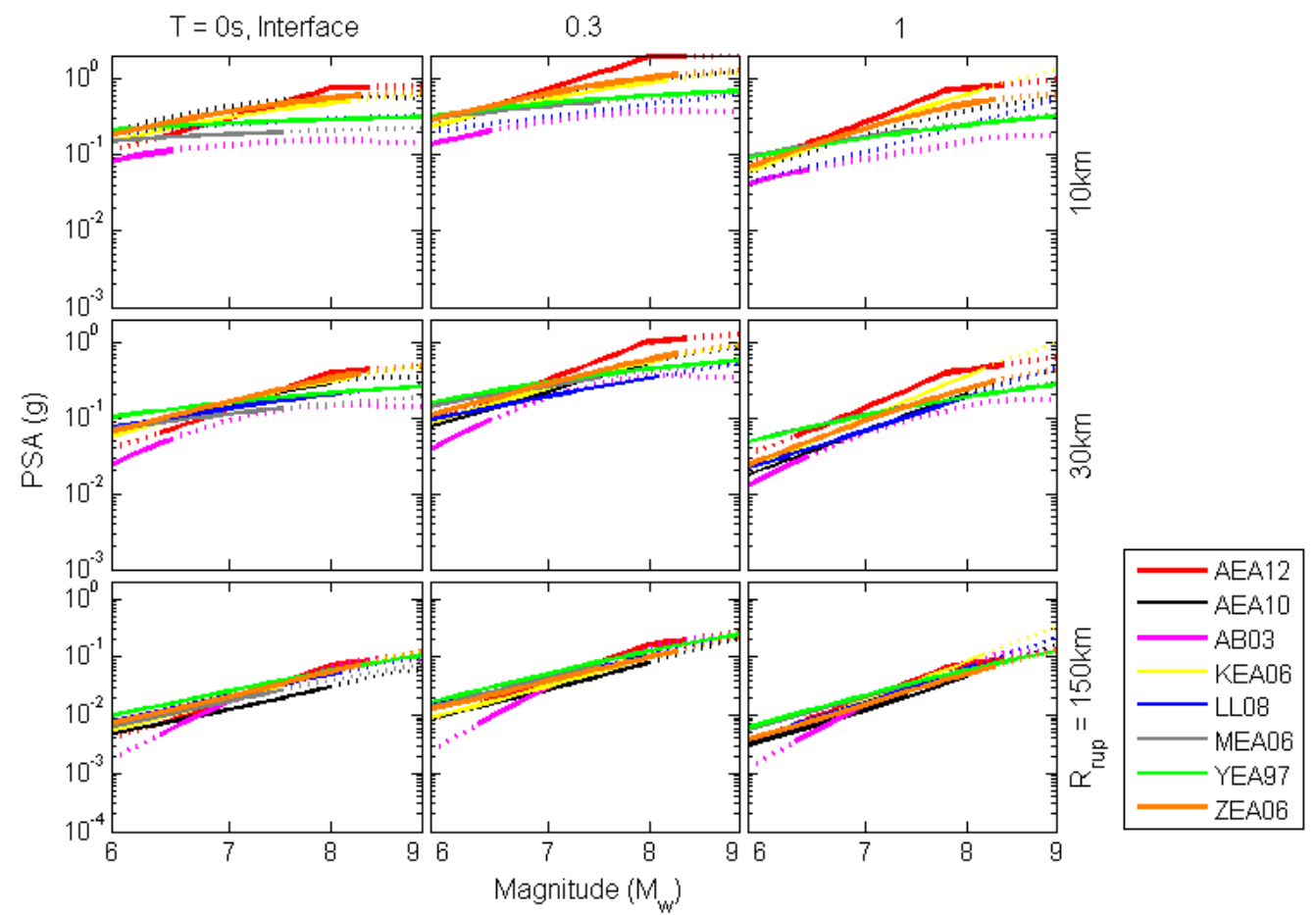

Figure 7.Trellis chart showing magnitude-scaling of predicted PSAs for pre-selected interface SZ GMPEs for various structural periods and source-to-site distances for rock site conditions. Dashed lines indicated where the scenario falls outside the magnitude-distance range of validity of the model. 
As shown in Figure 8, distance attenuation rates are quite variable among the GMPEs, particularly at magnitudes of 8 and 9. At those large magnitudes, the AB03 model for interface events shows relatively flat attenuation rates whereas AEA12, KEA06, and ZEA06 have relatively steep attenuation rates. These differences may reflect regional variations (i.e., genuine epistemic uncertainty) as the AB03 model is drawn heavily from Central and South American data, whereas AEA12, KEA06, and ZEA06 are based largely or entirely upon data from Japan. This issue is explored further in the model-data comparisons presented in the next section. All of the models have magnitude-dependent distance attenuation rates.

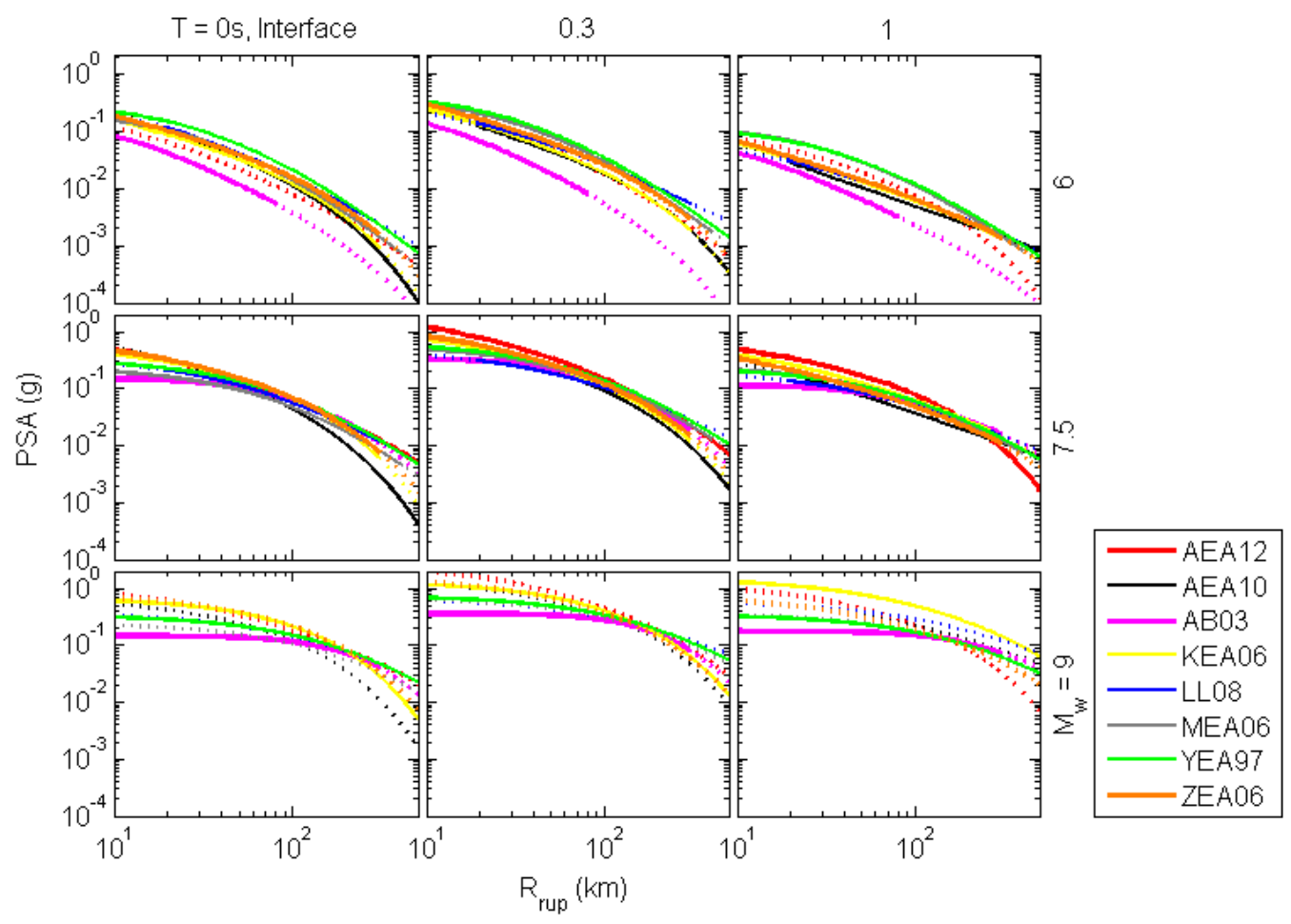

Figure 8.Trellis chart showing distance decay of predicted PSAs for pre-selected interface SZ GMPEs for various structural periods and magnitudes for rock site conditions. Dashed lines indicated where the scenario falls outside the magnitude-distance range of validity of the model.

Predictions from the AB03 model for interface events are typically a lower bound on estimates from the other considered GMPEs (Figure 6), except at long distances from very large earthquakes where the flat decay curve leads to high predicted PSAs (Figure 8). The models of AEA12 and ZEA06 often predict spectral ordinates at the upper end of the spread of the spectra. Predictions from the other GMPEs are more grouped particularly within the rough center of the distribution of available data from interface SZ events $\left(M_{w} 6\right.$ to 7 and $R$ from 50 to $150 \mathrm{~km}$ ) (Figure 6). 
Figure 9 shows attributes of $V_{s 30}$-scaling in site response functions for SZ GMPEs. The SZ GMPEs predict similar $V_{s 30}$-scaling, except for the KEA06 model, which predicts higher amplification for slow $V_{s 30}$ than the other GMPEs. Only three of the considered GMPEs account for nonlinear site response (AEA12, AB03 and MEA06). In GEM, ground motions will need to be predicted on soil sites close to the largest subduction events; therefore, models that include a nonlinear site term are favored.
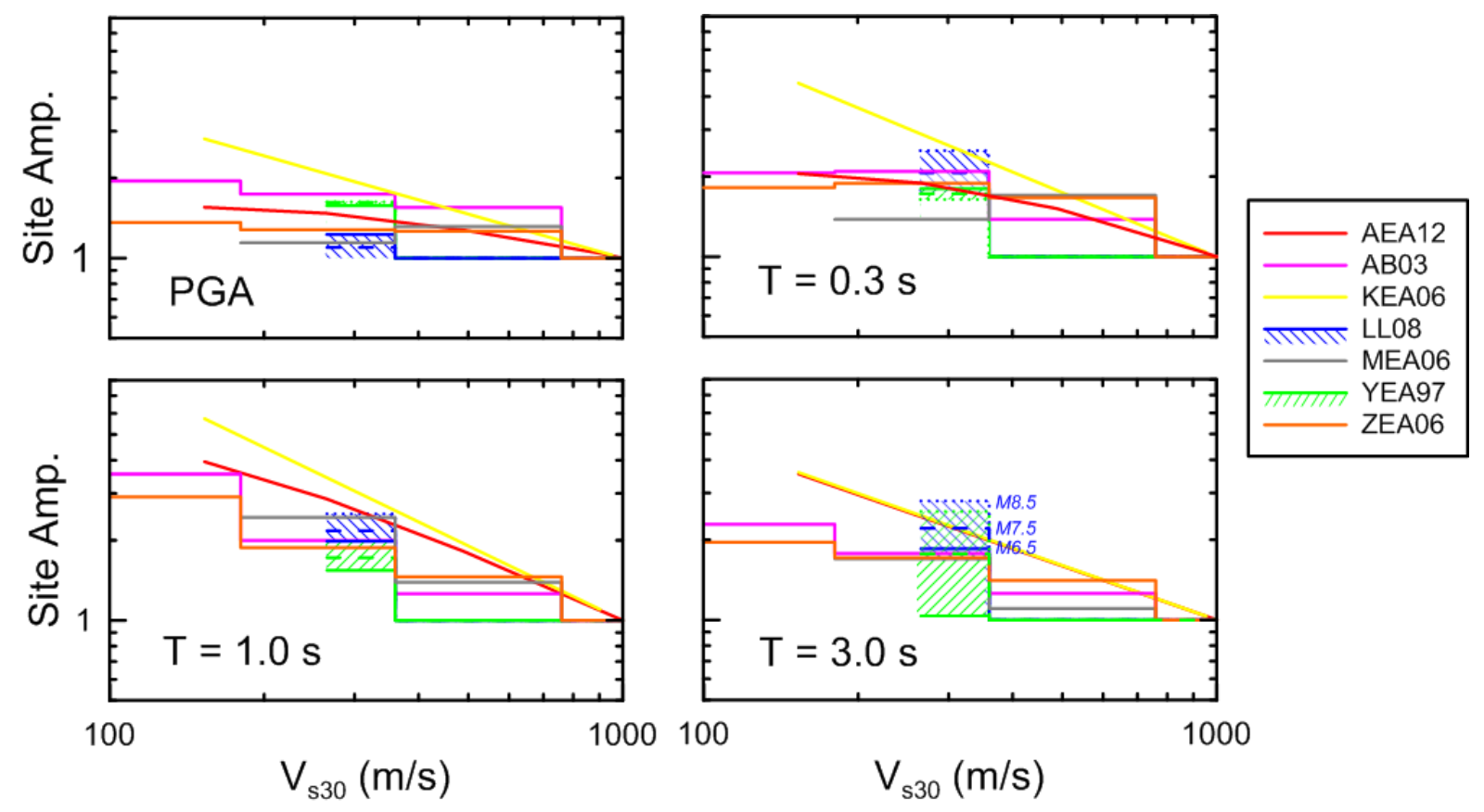

Figure 9. Trellis chart showing $V_{s 30}$-scaling of the SZ GMPEs for a reference rock peak acceleration of $P G A_{r}=0.1 \mathrm{~g}$. Amplification has been computed relative to a consistent reference velocity of $V_{r e f}=$ $1000 \mathrm{~m} / \mathrm{s}$, regardless of the reference condition used in the GMPE. Stepped relationships (e.g., AB03) describe site response relative to discrete categories whereas continuous relations use $V_{s 30}$ directly as the site parameter. The range shown for LL08 and YEA97 occurs because these relations do not have a formal site term but alternative GMPEs for rock and soil sites and, therefore, the differences are magnitude and distance dependent.

\section{STABLE CONTINENTAL REGIONS (SCRs)}

Figure 10 shows the PSAs from the ten pre-selected GMPEs. The variations among predictions is large in comparison to other regimes (sometimes up to a factor of ten), particularly at higher magnitudes and closer distances. This is to be somewhat expected since there are practically no strong-motion records from earthquakes in SCRs for these magnitude-distance ranges and the manner in which the models extrapolated will vary substantially between investigators. This comparison also shows that certain models predict greatly different PSAs than the majority of GMPEs at given distances and magnitudes. For example, DEA06 predicts much lower spectra at close distances, whereas the predicted 
spectra from SEA09 (Craton model) show a 'bump' at around 1s. Both these features are the result of choices in modeling to capture local characteristics in the areas for which these GMPEs were derived. DEA06 assumed particularly deep focal depths when deriving their model (using Joyner-Boore distance as a predictor variable in the GMPEs) for southern Norway, which leads to low near-source motions. SEA09 developed their model for the Yilgarn Craton in Western Australia, which has a specific combination of shallow earthquakes and a crustal structure that leads to large surface waves. The local peculiarities of these models mean that they may not be applicable for other SCRs that do not have these characteristics.

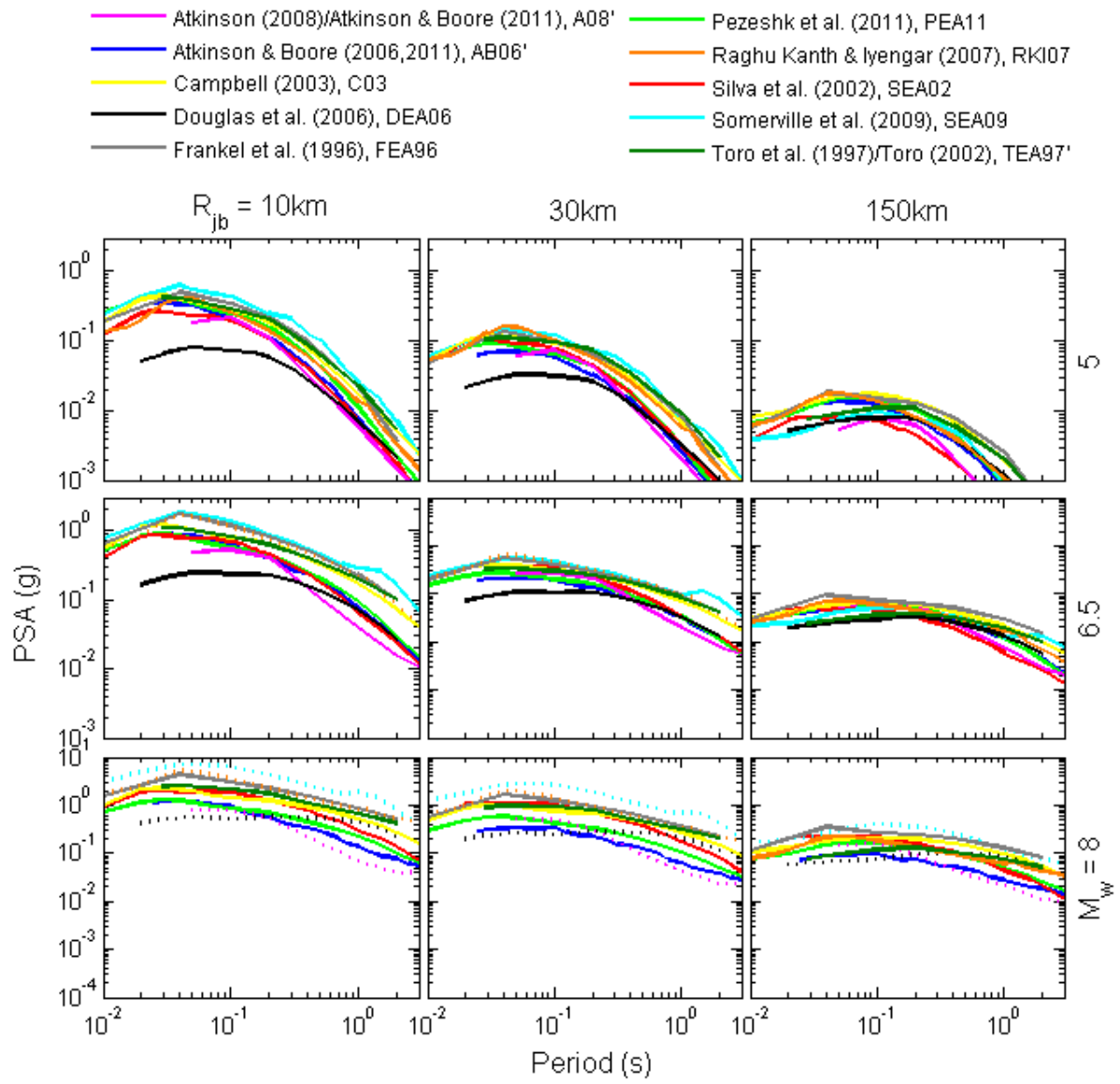

Figure 10.Trellis chart showing predicted PSAs for pre-selected SCR GMPEs for various earthquake scenarios for rock site conditions. Dashed lines indicated where the scenario falls outside the magnitude-distance range of validity of the model. Abbreviations of these GMPEs are listed in the legend.

Figure 11 shows that the magnitude-scaling of the SCR GMPEs is quite variable with respect to magnitude saturation. Weak magnitude-saturation occurs in DEA06, FEA96, SEA09, and RKI07, which in some cases leads to the prediction of potentially unrealistically- 
large PSAs from large earthquakes, particularly at long periods. Other models include stronger magnitude-saturation terms, which may be preferable for GEM application.

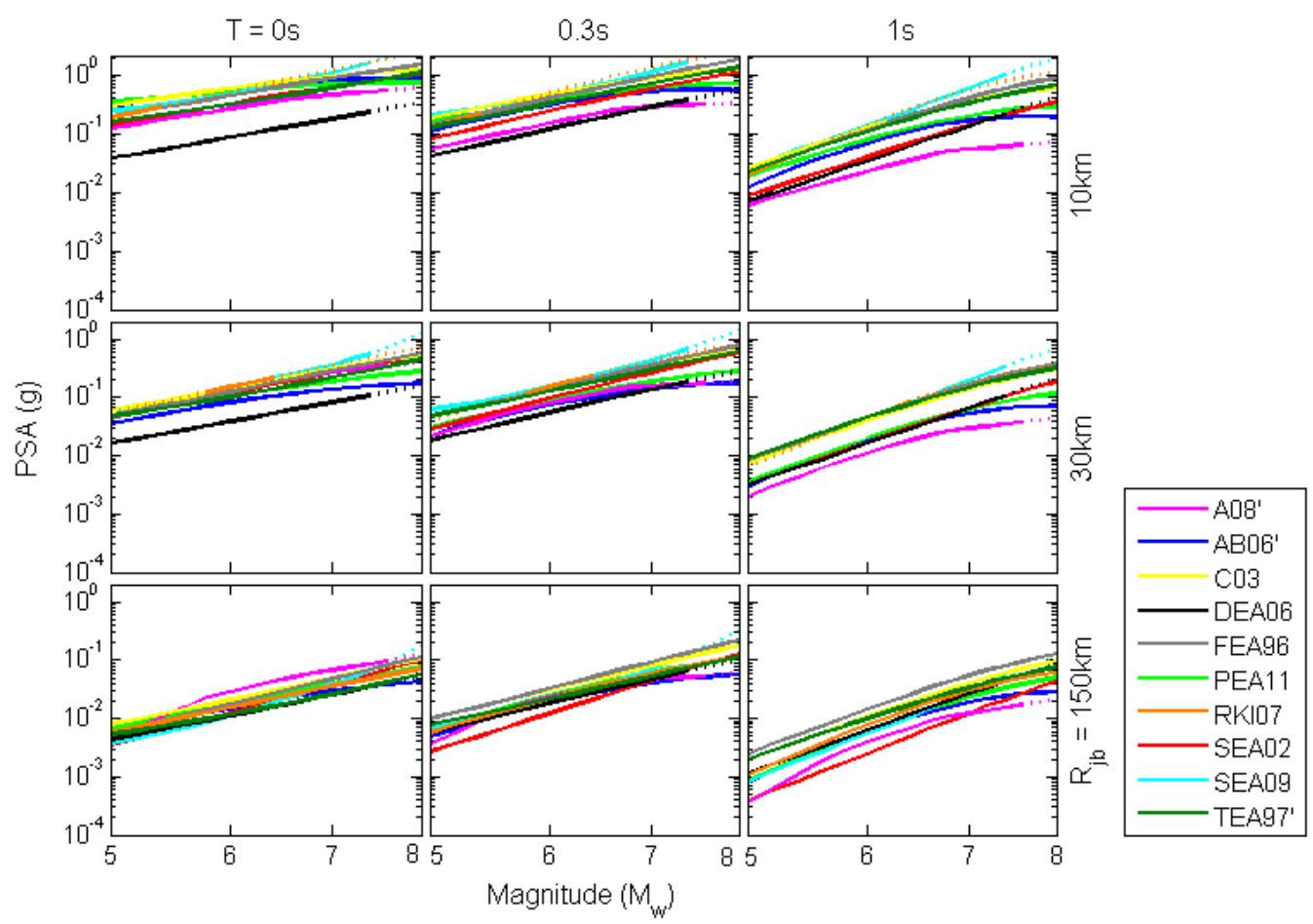

Figure 11.Trellis chart showing magnitude-scaling of predicted PSAs for pre-selected SCR GMPEs for various structural periods and source-to-site distances for rock site conditions. Dashed lines indicated where the scenario falls outside the magnitude-distance range of validity of the model.

Figure 12 shows the predicted distance attenuation of the ten models, which again are quite variable. Many of these models were developed for central and eastern North America, and reflect a change towards flatter attenuation associated with Moho bounce effects between 70 and $140 \mathrm{~km}$ (AB06', C03, FEA96 and PEA11). Other models for this same region (SEA02 and TEA97) do not model such effects. To account for epistemic uncertainty in the modeling of the effect of crustal structure and the requirement of global applicability of the selected GMPEs, it was considered desirable to select models that fall in both these categories. Another observation that can be made from Figure 12 is that for very large earthquakes AB06 is often a lower-bound on the predictions and SEA09 is generally the upper bound. 


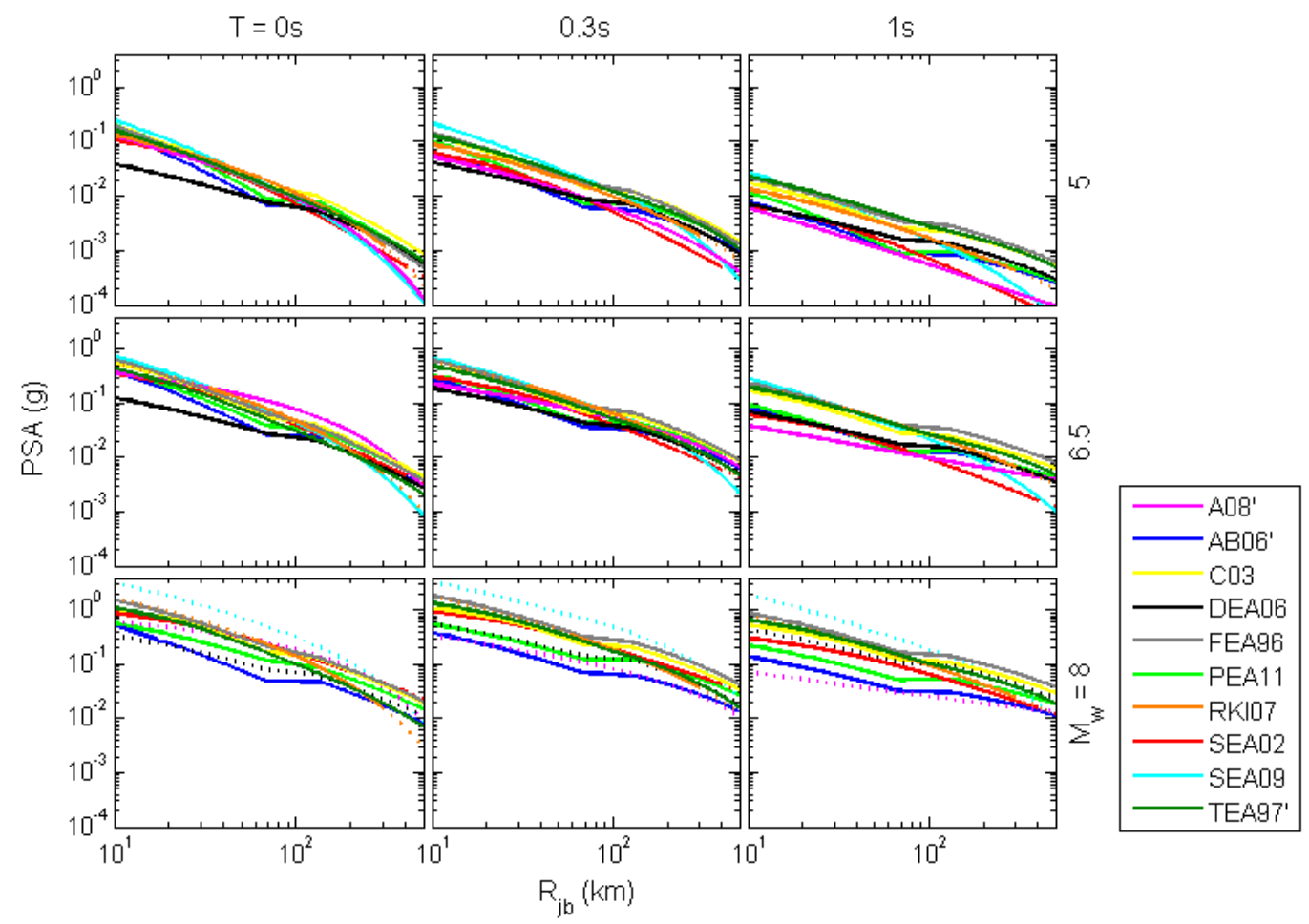

Figure 12.Trellis chart showing distance decay of predicted PSAs for pre-selected SCR GMPEs for various structural periods and magnitudes for rock site conditions. Dashed lines indicated where the scenario falls outside the magnitude-distance range of validity of the model.

Almost all of the SCR GMPEs do not include site terms allowing the ground motions on non-rock sites to be predicted. Only A08', AB06' and RKI07 include such terms; these are shown for NEHRP classes B-E in Figure E.3 (electronic supplement). In the case of A08' and AB06' these were adopted from results for ACRs. In the case of RKI07 the predicted nonlinear effects are very strong and the amplifications are not smooth but show large periodto-period variations, which we consider unrealistic. Most of the SCR GMPEs apply for hard rock site conditions with reference velocities much faster than those used as the reference in typical empirical site factors for ACRs or SZs (e.g., 760 or around $1000 \mathrm{~m} / \mathrm{s}$ ). Accordingly, for those models, before site factors of the type shown in Figures 4, 5, and 9 can be applied, an additional correction to adjust from hard rock to around $1000 \mathrm{~m} / \mathrm{s}$ must be made. This correction is generally not provided in the SCR GMPE documentation, nor is it well defined elsewhere in the literature. The aforementioned weaknesses with the SCR GMPE site terms are discussed further below with our recommendations.

The standard deviation terms associated with the SCR GMPEs (Figure 13) show substantial model-to-model differences. These standard deviation models are generally a direct consequence of the simulation method used and the variability in the input parameters, 
rather than the result of statistical comparisons between data and prediction. The standard deviations associated with RKI07 are much lower than those from the other models because only the parametric component of the variability was included rather than also including the modeling component. This argues against its selection. The standard deviation models of DEA06, SEA02, and SEA09 show strong period dependencies, which are not observed in the SZ or ACR GMPEs. We are of the opinion that this argues against selecting these models. Only three of the ten GMPEs separate standard deviations into between- and within-event components, which is valuable for some analyses. E06 (EPRI, 2006) proposed generic standard deviation models for SCR GMPEs, which were considered as possible replacements for those standard deviations that were not thought to be physically realistic or are not spilt into the two components.

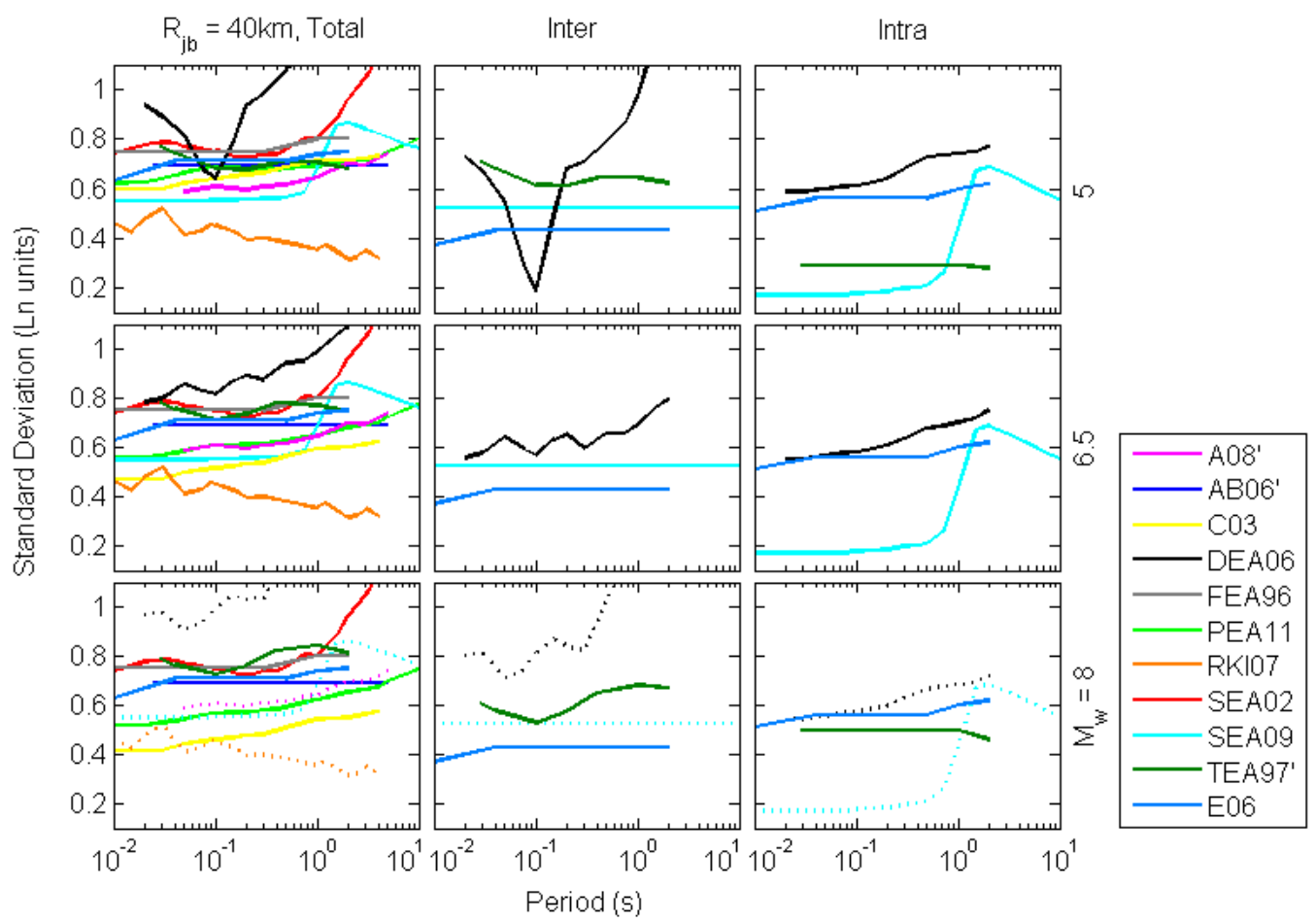

Figure 13. Trellis chart showing inter- (between) and intra-(within) event and total natural log standard deviations of the pre-selected SCR GMPEs. 


\section{GMPE-DATA COMPARISONS}

\section{CRITERIA FOR ACCEPTING GMPE-DATA COMPARISON STUDIES FOR USE IN MODEL SELECTION}

GMPEs for SZs and ACRs are most often developed from the regression of empirical strong-motion data; thus, model-data comparisons are integral to the process by which they are prepared. Nonetheless, GMPE-data comparisons were considered a critical component of the selection process. GMPEs derived for SCRs are generally based on ground-motion simulations and, therefore, model-data comparisons are even more important for these equations. The value of these comparisons is often derived from the comparison data set being beyond the parameter space considered for the original GMPE. For example, the data may be derived from a different region from that used in the original model development, which can be useful for studies of model applicability to the data region and regional variations of ground motions generally. Another significant example specific to SZs is the recent availability of data sets from large-magnitude earthquakes (M 8.8 Maule, Chile; and M 9.0 Tohoku, Japan) beyond the upper-bound magnitudes available during GMPE development.

Most GMPE-data comparisons in the literature consist of plots of ground-motion intensity measures versus distance along with GMPE median trend curves. Plots of this type have limited applicability for formal analysis of GMPE performance because it can be difficult to judge trends when the data span a very wide range on the amplitude axis and because eventspecific bias (event terms) are seldom taken into account. Accordingly, we restrict our literature compilation for SZs and ACRs to studies that include a formal analysis of residuals into the GMPE-data comparisons. This still leads to a considerable number of studies (8 for SZs and 13 for ACRs). For SCRs, however, restricting our compilation to only this type of analysis would lead to considering only one or two studies. Hence, it was decided for SCRs to also compile those studies only showing plots of predicted against observed ground motions. Even with this relaxation of the criterion, only a few studies were identified.

The three general methods of relatively rigorous model-data comparisons present in the collected literature are: (1) the maximum-likelihood approach of Scherbaum et al. (2004) and its extension to normalized within- and between-event residuals distributions by Stafford et al. (2008), which is intended to judge the overall fit of model to data; (2) the information theoretic approach of Scherbaum et al. (2009) for model-data comparisons, which also 
produces various overall goodness-of-fit metrics; and (3) analysis of within- and betweenevent residuals specifically targeted to investigations of GMPE scaling with respect to magnitude, distance, and site parameters (e.g., Scasserra et al., 2009).

\section{APPLICATION FOR GMPE SELECTION IN THIS STUDY}

Tables 1 and 2 summarize the model-data comparisons considered in this study for ACRs and SZs, respectively. More information on each considered study and its individual findings are given in a consistent format within Appendix A of Stewart et al. (2013). The columns in Tables 1 and 2 indicate the GMPEs that were tested, whereas the rows correspond to the model-data comparison studies.

Table 1. Summary of studies in literature with quantitative model-data comparisons for ACRs. Rows with light gray shading are for studies using an overall goodness-of-fit approach, rows with dark grey shading are for studies that test specific GMPE attributes through residuals analysis.

\begin{tabular}{|c|c|c|c|c|c|c|c|c|c|}
\hline & AS & AB & BA & CB & FEA10 & CY \\
2008 & 2010 & 2008 & 2008 & KEA & MEA & ZEA \\
2006 & 2006 & 2006 \\
\hline A (Euro-Med) & & $\mathrm{X}$ & $\mathrm{X}$ & & & & & & \\
\hline B (Iran) & & & $\mathrm{X}$ & $\mathrm{X}$ & & $\mathrm{X}$ & & & \\
\hline C (Worldwide) & $\mathrm{X}$ & $\mathrm{X}$ & $\mathrm{X}$ & $\mathrm{X}$ & $\mathrm{X}$ & $\mathrm{X}$ & $\mathrm{X}$ & & $\mathrm{X}$ \\
\hline $\mathrm{D}$ (CA) & $\mathrm{X}$ & & $\mathrm{X}$ & $\mathrm{X}$ & & $\mathrm{X}$ & & & \\
\hline $\mathrm{E}$ (Japan) & $\mathrm{X}$ & & $\mathrm{X}$ & $\mathrm{X}$ & & $\mathrm{X}$ & & & \\
\hline $\mathrm{F}$ (Portugal) & & $\mathrm{X}$ & $\mathrm{X}$ & & & $\mathrm{X}$ & & & \\
\hline G (Japan) & $\mathrm{X}$ & $\mathrm{X}$ & $\mathrm{X}$ & & $\mathrm{X}$ & $\mathrm{X}$ & $\mathrm{X}$ & & $\mathrm{X}$ \\
\hline $\mathrm{H}$ (Italy) & $\mathrm{X}$ & $\mathrm{X}(07)$ & $\mathrm{X}$ & $\mathrm{X}$ & & $\mathrm{X}$ & & & \\
\hline $\mathrm{I}$ (Greece) & & & $\mathrm{X}$ & & & & & & \\
\hline J (Iran) & & & $\mathrm{X}$ & $\mathrm{X}$ & & $\mathrm{X}$ & & & \\
\hline K (Japan) & $\mathrm{X}$ & & $\mathrm{X}$ & $\mathrm{X}$ & & $\mathrm{X}$ & $\mathrm{X}$ & & \\
\hline L (NZ) & & & $\mathrm{X}$ & & & $\mathrm{X}$ & & $\mathrm{X}$ & $\mathrm{X}$ \\
\hline M (CA) & $\mathrm{X}$ & & $\mathrm{X}$ & $\mathrm{X}$ & & $\mathrm{X}$ & & & \\
\hline
\end{tabular}

$A=$ Stafford et al. (2008); $B=$ Ghasemi et al. (2008, 2009); $C=$ Delavaud et al. (2012); $D=$ Kaklamarios and Baise (2011); $E=$ Nishimura (2010); $F=$ Vilanova et al. (2012); $G=$ Beauval et al. (2012); H = Scasserra et al. (2009); I = Margaris et al. (2010); J = ShojaTaheri et al. (2010); $\mathrm{K}=$ Uchiyama and Midorikawa (2011); L = Bradley (2012, in press); $M=$ Liao and Meneses (2012) 
Table 2. Summary of studies in literature with quantitative model-data comparisons for SZs. Rows with light gray shading are for studies using an overall goodness-of-fit approach, rows with dark gray shading are for studies that test specific GMPE attributes through residuals analysis.

\begin{tabular}{|c|c|c|c|c|c|c|c|c|c|}
\hline & $\begin{array}{c}\text { AEA } \\
2012\end{array}$ & $\begin{array}{c}\text { AEA } \\
2010\end{array}$ & $\begin{array}{c}\text { AB } \\
2003\end{array}$ & $\begin{array}{c}\text { GEA } \\
2005\end{array}$ & $\begin{array}{c}\text { KEA } \\
2006\end{array}$ & $\begin{array}{c}\text { LL } \\
2008\end{array}$ & $\begin{array}{c}\text { MEA } \\
2006\end{array}$ & $\begin{array}{c}\text { YEA } \\
1997\end{array}$ & $\begin{array}{c}\text { ZEA } \\
2006\end{array}$ \\
\hline A (S. Amer) & $\mathrm{X}$ & $\mathrm{X}$ & $\mathrm{X}$ & $\mathrm{X}$ & & & $\mathrm{X}$ & $\mathrm{X}$ & $\mathrm{X}$ \\
\hline B (L. Antilles) & & & $\mathrm{X}$ & $\mathrm{X}$ & $\mathrm{X}$ & $\mathrm{X}$ & $\mathrm{X}$ & $\mathrm{X}$ & $\mathrm{X}$ \\
\hline $\begin{array}{c}\text { C (India- } \\
\text { Burma) }\end{array}$ & & & $\mathrm{X}$ & & & & & & \\
\hline D (Greece) & & & $\mathrm{X}$ & & $\mathrm{X}$ & $\mathrm{X}$ & $\mathrm{X}$ & $\mathrm{X}$ & $\mathrm{X}$ \\
\hline $\mathrm{E}$ (Global) & $\mathrm{X}$ & $\mathrm{X}$ & $\mathrm{X}$ & & $\mathrm{X}$ & $\mathrm{X}$ & $\mathrm{X}$ & $\mathrm{X}$ & $\mathrm{X}$ \\
\hline $\mathrm{F}$ (NZ) & & & $\mathrm{X}$ & & & & $\mathrm{X}$ & & $\mathrm{X}$ \\
\hline G (Chile) & & & $\mathrm{X}$ & & & & & & $\mathrm{X}$ \\
\hline H (Japan) & & & $\mathrm{X}$ & & & & & & $\mathrm{X}$ \\
\hline
\end{tabular}

$\mathrm{A}=$ Arango et al. (2012); $\mathrm{B}=$ Douglas and Mohais (2009); C = Gupta (2010); D = Delavaud et al. (2012); $\mathrm{E}=$ Beauval et al. (2012); $\mathrm{F}=$ Bradley (2010); $\mathrm{G}=$ Boroschek et al. (2012); H = Stewart et al. (2013, in press)

For ACRs, the most often tested models are the NGA models of AS08, BA08 (which is the single most-tested model), CB08, and CY08. Many of the studies seek to evaluate the applicability of the global NGA models to specific regions, including Europe, Japan, Iran, and New Zealand. The overall goodness-of-fit approaches find varying levels of fit for these and other models. Sometimes when poor fits are encountered, relatively-local GMPEs that fit the data better are recommended, but such models are likely to not extrapolate well to larger magnitude events. None of the NGA models or other pre-selected models stands out as clearly superior from these studies. Somewhat more useful are the second type of model-data comparisons in which specific GMPE attributes are tested. These studies find some instances of misfits in distance attenuation trends. In some cases when the data driving the misfit are from small magnitude events outside the range of applicability of the original models, a model by Chiou et al. (2010) performs well, although this was not a GEM pre-selected model from Task 2 because it only provides coefficients for a few structural periods.

For SZs, the most often tested models are AB03 and ZEA06, which reflect data globally and from Japan, respectively. The studies point rather clearly towards regional variations in subduction ground motions. Overall goodness-of-fit approaches find Japan-based models such as ZEA06 performing better than other models for Japanese data. Those studies also 
find that the AB03 model performs relatively poorly against Japanese and Greek data (e.g., Beauval et al. 2012; Delavaud et al., 2012) and relatively well against central and south American data (Arango et al., 2012). The AEA12 model, while tested relatively sparsely, has generally performed well in the tests. As with ACRs, somewhat more useful were the modeldata comparisons in which specific GMPE attributes were tested. Applications of this approach to the Maule (Chile) and Tohoku (Japan) data (Boroschek et al, 2012; Stewart et al., 2013) identified different distance attenuation trends from these large events. In the case of the Maule earthquake, the relatively slow distance attenuation of the AB03 model provided a good fit to the data; whereas the Tohoku data attenuated relatively fast with distance and was better matched by the model of ZEA06.

Table E.2 presents the model-data comparisons considered in this study for SCRs. Most of the studies show plots of recorded data against median fit lines, and between-event variability is not considered in the analysis or interpretation. Very few quantitative comparisons of the type undertaken for SZs and ACRs have been performed, and these have not provided conclusive results. We note that the AB06' model has been the most well-tested model for SCRs.

\section{RECOMMENDED GMPES}

The GEM-PEER Task 3 core working group developed consensus (or near-consensus) selections based on the criteria and information presented previously for the ACR, SZ, and SCR regimes. Those selections were carefully reviewed via an in-person meeting and written correspondence by all of the project experts (Table E.1). Based on expert feedback, final recommendations for GMPEs to be used by GEM for hazard calculations were developed as described in this section.

\section{ACTIVE CRUSTAL REGIONS}

The following three models were selected for ACRs: AB10 (Akkar and Bommer, 2010), CY08 (Chiou and Youngs, 2008), and ZEA06 (Zhao et al., 2006). These models provide a good geographical spread (one for Europe and the Middle East, one global, and one

predominantly for Japan). Their scaling characteristics show desirable features, such as magnitude and distance saturation and anelastic attenuation terms, which means that they can be applied across the magnitude-distance range of interest to GEM. CY08 was preferred over the other pre-selected NGA models because: (1) its magnitude-scaling for small and 
moderate events was considered to be more appropriate than the other NGA models and (2) it has an anelastic attenuation term that has produced relatively favorable model-data comparisons in past studies. The BA08 model was seriously considered for selection as an alternative or supplement to CY08 as it also has generally compared well to international data and has many of the desirable functional form attributes of CY08 (but with simpler equations). It was not selected because we did not want to have four ACR models.

Figures E.4-E.6 present re-plots of the ACR trellis diagrams that highlight the selected models by graying out the predictions from the non-selected GMPEs. The figures present response spectra, magnitude scaling, distance scaling, and standard deviation terms for ACR events and rock site conditions. These plots show how the selected models reflect the range of behavior observed in the pre-selected GMPEs.

Each of the selected ACR models includes site terms, but we do not recommend application of the linear site terms of AB10 or ZEA06. The ZEA06 and AB10 models should be used for hard rock and rock conditions, respectively (assumed $V_{r e f}=1000 \mathrm{~m} / \mathrm{s}$ ). The nonlinear site amplification function from CY08 can be applied to correct the ground motions for the $V_{s 30}$ of the site. The CY08 amplification function was developed relative to a reference condition of $1130 \mathrm{~m} / \mathrm{s}$, which is sufficiently close to $1000 \mathrm{~m} / \mathrm{s}$ that the model can be directly applied without significant bias.

There was some discussion about whether epistemic uncertainty in ground motions in ACRs is being sufficiently captured by these three models since for some magnitudes and distances the three sets of results are quite similar (e.g., Figure E.4). After some deliberation, we decided to not select a fourth GMPE or to scale up or down one of the selected models. However, we note that the within-event standard deviation terms of the selected models (Figure E.7) have significant differences, reflecting epistemic uncertainty.

\section{SUBDUCTION ZONES}

We have selected the recent global model of AEA12 (Abrahamson et al, 2012; also known as the 'BC Hydro' model), the global model of AB03 (Atkinson and Boore, 2003) and the Japanese model of ZEA06 (Zhao et al, 2006). These models were preferred since they are based on large data sets, have desirable attributes in terms of their magnitude and distance scaling functions, have been checked against data from well-recorded earthquakes (including 2010 Maule Chile and 2011 Tohoku Japan), and produce different distance attenuation trends 
that have been shown to match data trends from different global regions (thus bringing into the selection a representation of genuine epistemic uncertainty).

There was some debate over inclusion of the AB03 model since the predicted decay rate from large $\left(\mathrm{M}_{\mathrm{w}}>8\right)$ interface earthquakes is slow, meaning that the ground motions at great distances $(>100 \mathrm{~km})$ are not substantially reduced from those closer to the source. This behavior was considered physically unlikely by some members of the Task 3 expert panel, who therefore recommended that the model be rejected. Nevertheless, it was decided to retain this model since the slow decay rate has been observed in some earthquakes (e.g., Maule Chile; Boroschek et al., 2012) and this model has been shown to work well in model-data comparisons for smaller magnitude events as well (e.g., study A in Table 2). Moreover, since variable distance attenuation rates are observed across global data sets for interface subduction zone earthquakes, and the AEA12 and ZEA06 models have relatively fast distance attenuation rates, use of the AB03 model was considered desirable to capture this important source of epistemic uncertainty. Nonetheless, we never reached full consensus on the selection of this particular model and no strong alternative model emerged during discussions.

Figures E.8-E.11 present re-plots of the trellis diagrams for SZs that highlight the selected models by graying out the predictions from the non-selected GMPEs. The figures present response spectra, magnitude scaling, distance scaling, and standard deviation terms for interface subduction events and rock site conditions. Additional similar plots for in-slab subduction events are presented in the Appendix of Stewart et al. (2013). These plots show how the selected models reflect the variable rates of distance attenuation in pre-selected models.

Each of the selected SZ models includes site terms, but we do not recommend application of the linear site terms of ZEA06. Instead, the ZEA06 model should be used for hard rock conditions (assumed $V_{r e f}=1000 \mathrm{~m} / \mathrm{s}$ ) and the nonlinear site amplification function from AEA12 applied to these hard-rock estimates. Since the assumed reference velocity is $V_{r e f}=1000 \mathrm{~m} / \mathrm{s}$ for ZEA06 and the AEA12 site terms have period-dependent (and unspecified) values of $V_{\text {ref }}$, the appropriate site correction can be computed as follows from the AEA12 model (where $f$ is the site function in natural log units):

1. Compute site amplification using the appropriate $V_{s 30}$ for the site: $f_{\text {site }}\left(V_{s 30}, P G A_{r}\right)$; 
2. Compute site amplification for $V_{r e f}=1000 \mathrm{~m} / \mathrm{s}: f_{r e f}\left(1000 \mathrm{~m} / \mathrm{s}, P G A_{r}\right)$; and

3. Calculate site amplification relative to $V_{\text {ref: }}$ $f_{\text {site }}\left(V_{s 30}, P G A_{r}\right)-f_{\text {ref }}\left(1000 m / s, P G A_{r}\right)$.

\section{STABLE CONTINENTAL REGIONS}

There was unanimous consensus on the selection of the PEA11 (Pezeshket al., 2011) GMPE. Several lines of reasoning supported this selection - it is based on the hybrid empirical technique, which has desirable attributes, and uses a recent and fairly complete data set for eastern North America (ENA). Furthermore, it can be considered an update of C03 (Campbell, 2013, in press). AB06' (Atkinson and Boore, 2006, 2011) was also chosen. Arguments for this model, which is based on finite-source stochastic simulations, include the effective calibration of input parameters against available data, its broad usage in previous forms (including US national hazard maps), an ability to apply the model for either very hard rock conditions or for $V_{s 30}=760 \mathrm{~m} / \mathrm{s}$ conditions (thus avoiding the need for correction factors to very hard rock conditions), and its position as the most prominent and well documented of the stochastic procedures. An argument against its selection is that elements of the model are similar to PEA11, so it can be argued that the use of PEA11 and AB06' may artificially lower epistemic uncertainty. SEA02 (Silva et al., 2002; double corner model with saturation) was the third model selected. The principal argument for this stochastic GMPE is its use of a point-source double corner model for the source spectrum, which has more realistic characteristics than single corner models with respect to long period (> 1 s) spectral ordinates. Single-corner models tend to overpredict observed long-period ground motions whereas double-corner source spectra generally match these motions better, which could be important for applications involving high-rise buildings and other long-period structures.

The three selected models of PEA11, AB06', and SEA02 were all developed for application in the central and eastern U.S. To increase the geographical spread of the selected GMPEs we considered including the model SEA09 (Somerville et al., 2009; Craton model) in lieu of the SEA02 model. The craton version of SEA09 applies to a SCR that is distinct geographically from ENA, which dominates many of the other pre-selected GMPEs. Moreover, this GMPE was developed using a different simulation procedure (a hybrid of stochastic simulations at high frequencies and physics-based modeling at low frequencies). The diversity of the study region and simulation techniques were cited as advantages of this model. However, the weaknesses of this model were eventually considered to be too strong to 
select it. These weaknesses include: relatively poor documentation, some features of the model are specific to the study region and may not extrapolate well globally (e.g., properties of shallow earthquakes and large Moho bounce effect), the magnitude-scaling does not saturate but increases in slope with magnitude at short periods (Figure 11), and the standard deviation term has an unrealistic step at around 1s (at the interface of the stochastic and physical models; Figure 13).

Figure E.12 highlights predicted spectra from PEA11, AB06', and SEA02 by graying out the predictions from the other GMPEs. These graphs show that the predictions from these three models are quite similar. We felt that this similarity in predictions does not accurately reflect the epistemic uncertainty in SCR GMPEs, which should be quite large given the lack of data. Therefore, we felt that some additional uncertainty should be introduced into the ground-motion logic tree for SCRs by adding another model. Various ways of generating this additional model were considered. This included the idea of scaling up or down one of the already selected GMPEs (the so-called backbone approach) but this was considered too arbitrary a method since it was difficult to decide on a scaling factor. In the end it was decided to bring in a model that was not originally selected.

Therefore, following much discussion we decided to select the GMPE of TEA97' (Toro et al., 1997; Toro, 2002). Although this model is also for ENA, its predictions are significantly different from those of the other three models. In addition, its modeling of epistemic uncertainty and aleatory variability is the most sophisticated of all stochastic models and it has been used successfully in many previous projects. However, the data analyzed for this model are now more than 20 years old (it was originally published as part of an EPRI report in 1993).

Figures E.12-E.16 present re-plots of the trellis diagrams for SCRs that highlight the four selected models by graying out the predictions from the non-selected GMPEs. The figures present response spectra, magnitude scaling, distance scaling, and standard deviation terms for rock site conditions. These plots show that the selected models approximately reflect the range of behavior observed in the pre-selected GMPEs.

Of the four selected models, only AB06' includes recommendations for modeling site amplification. The AB06' model can be applied for hard rock reference conditions $\left(V_{s} \geq 2.0\right.$ $\mathrm{km} / \mathrm{s}$; NEHRP Class A) or the NEHRP BC boundary $\left(V_{s 30}=760 \mathrm{~m} / \mathrm{s}\right)$. When the BC model is used, a site amplification function can be applied, which was adopted from an empirical study of site amplification for active crustal regions (Choi and Stewart, 2005). It is unknown 
whether those site amplification functions are applicable to the SCRs, although this is an area of active research in the NGA-East project (http://peer.berkeley.edu/ngaeast/).

As mentioned previously, there are problems with the standard deviation functions in some of the selected SCR GMPEs. We recommend application of the standard deviation terms from AB06', PEA11, and TEA97' in their as-published form (shown in Figure E.16). We recommend that the standard deviations of EPRI (2006) be used in lieu of those from SEA02 because of the large increase in standard deviations for $T>1 \mathrm{~s}$ for SEA02, which we consider unrealistic.

\section{SUMMARY AND CONCLUSIONS}

In this article we have presented and applied a method for selection of ground-motion models for the GEM-PEER Global GMPEs Project. This procedure aimed to be transparent, objective and repeatable in future projects (e.g., for possible updates of the GEM hazard assessments). The procedure consists of expert review of several information sources, including: (1) trellis plots showing the scaling of candidate GMPEs against period, magnitude, distance, and site condition, along with within- and between-event standard deviation terms; (2) functional forms of candidate GMPEs; and (3) review of quantitative model-data comparison studies in the literature.

Based on expert review of the aforementioned information sources, a set of GMPEs for each of the tectonic regimes was proposed as described in the previous section. These consisted of three GMPEs for subduction zones, three GMPEs for active crustal regimes and four GMPEs for stable continental regions. For the majority of these GMPEs their associated standard deviation models and site terms were selected as well. The only exception for the standard deviation component of the models was for stable continental regions where a standard deviation model by EPRI (2006) was preferred over that derived by Silva et al. (2002). In the case of site amplification models, we do not recommend the linear site amplification functions used in several of the selected GMPEs. In those cases, we recommend application of the GMPEs for reference rock site conditions in conjunction with nonlinear site corrections from the literature (details in Stewart et al., 2013).

We emphasize that the goal of this paper is to select a set of GMPEs for global hazard analysis; therefore, the number of selected GMPEs may be less than what might be used for site-specific analysis and/or development of national hazard maps. We also note that GMPE 
development is a continuously evolving research area, and new and/or updated GMPEs are regularly published as more empirical and simulated data become available and our knowledge of ground-motion hazard expands. Thus, the set of GMPEs recommended here should not be viewed as a long-term recommendation and should be re-evaluated on a regular basis.

\section{ACKNOWLEDGEMENTS}

This study was funded by the GEM Foundation as part of the Pacific Earthquake Engineering Research Center's (PEER's) Global GMPEs project. Any opinions, findings, and conclusions or recommendations expressed in this material are those of the authors and do not necessarily reflect those of the sponsors. Constructive feedback and comments received from many international experts involved in the GEM-PEER project are gratefully appreciated. We thank Carola Di Alessandro for her assistance with the collection and synthesis of data for this study and Emel Seyhan of UCLA for her assistance with the preparation of the site amplification figures in this article.

\section{REFERENCES}

Abrahamson, N., Gregor, N. and Addo, K., 2012. BCHydro ground motion prediction equations for subduction earthquakes, Earthquake Spectra, submitted.

Akkar, S. andBommer, J. J., 2010. Empirical equations for the prediction of PGA, PGV andspectral accelerations in Europe, the Mediterranean region and the Middle East, Seism. Res. Ltrs, 81:2, 195-206.

Allen, T. I. and Wald, D. J., 2009. On the use of high-resolution topographic data as a proxy for seismic site conditions (VS30), Bull. Seism. Soc. Am., 99: 2A, 935-943.

Arango, M. C., Strasser, F. O., Bommer, J. J.,Cepeda, J. M., Boroschek, R., Hernandez, D. A. and Tavera, H., 2012. An evaluation of the applicability of current ground-motion models to the South and Central American subduction zones, Bull. Seism. Soc. Am., 102:1, 143-168.

Atkinson, G. M. and Boore, D. M., 2011. Modifications to existing ground-motion prediction equations in light of new data, Bull. Seism. Soc. Am., 101:3, 1121-1135.

Atkinson, G. M. and Boore, D. M., 2006. Earthquake ground-motion prediction equations for eastern North America, Bull Seism. Soc. Am, 96:6, 2181-2205.

Atkinson, G. M. and Boore, D. M., 2003. Empirical ground-motion relations for subduction zone earthquakes and their application to Cascadia and other regions, Bull Seism. Soc. Am, 93:4, 17031729. 
Beauval C., Tasan, H., Laurendeau, A. Delavaud, E., Cotton, F., Guéguen, Ph. and Kuehn, N., 2012. On the testing of ground-motion prediction equations against small magnitude data, Bull. Seism. Soc. Am., 102, 1994-2007.

Boore, D. M. and Atkinson, G. M., 2008. Ground-motion prediction equations for the average horizontal component of PGA, PGV, and 5\%-damped PSA at spectral periods between $0.01 \mathrm{~s}$ and 10.0 s, Earthquake Spectra, 24:1, 99-138.

Boroschek, R., Contreras, V., Kwak, D.Y. and Stewart, J.P., 2012. Strong ground motion attributes of the $2010 \mathrm{M}_{\mathrm{w}} 8.8$ Maule Chile Earthquake, Earthquake Spectra, 28: S1, S19-38.

Bradley, B. A., 2012. A New Zealand-specific pseudo-spectral acceleration ground motion prediction equation for active shallow crustal earthquakes based on foreign models ," Bull Seism. Soc. Am., Submitted (used with permission).

Campbell, K. W. and Bozorgnia, Y., 2008. NGA ground motion model for the geometric mean horizontal component of PGA, PGV, PGD and 5\% Damped linear elastic response spectra for periods ranging from 0.01 to 10 s, Earthquake Spectra, 24:1, 139-171.

Campbell, K. W., 2013. A comparison of ground motion prediction equations developed for eastern North America using the hybrid empirical method, Bull Seism. Soc. Am., accepted.

Chiou, B., Youngs, R., Abrahamson, N., and Addo, K., 2010. Ground-motion attenuation model for small-to-moderate shallow crustal earthquakes in California and its implications onregionalization of ground-motion prediction models, Earthquake Spectra, 26, 907-926.

Chintanapakdee, C., Naguit, M.E. and Charoenyuth, M. 2008. Suitable Attenuation Model for Thailand, Proc. $14^{\text {th }}$ World Conf. Eqk. Eng., October, Beijing, China.

Chiou B.S-J. and Youngs, R.R., 2008. An NGA model for the average horizontal component of peak ground motion and response spectra, Earthquake Spectra, 24:1, 173-215.

Choi, Y. and Stewart, J.P., 2005. Nonlinear site amplification as function of $30 \mathrm{~m}$ shear wave velocity, Earthquake Spectra, 21:1, 1-30.

Cotton, F., Scherbaum, F., Bommer, J. J. and Bungum, H., 2006. Criteria for selecting and adjusting ground-motion models for specific target regions: Application to central Europe and rock sites, $J$. Seism., 10:2, 137-156.

Cramer, C. H., 2003. Site specific seismic hazard analysis that is completely probabilistic, Bull Seism. Soc. Am., 93, 1841-1846.

Delavaud, E., Scherbaum, F., Kuehn, N. and Allen, T., 2012. Testing the global applicability of ground-motion prediction equations for active shallow crustal regions, Bull Seism. Soc. Am., 102, 707-721 
Di Alessandro, C., Bozorgnia, Y., Abrahamson, N.A., Akkar, S. and Erdik, M., 2012. GEM - PEER Global Ground Motion Prediction Equations Project: An Overview, Proc. 15 $5^{\text {th }}$ World Conf. Eqk. Eng., Lisbon, Portugal.

Douglas, J., 2003. Earthquake ground motion estimation using strong-motion records: A review of equations for the estimation of peak ground acceleration and response spectral ordinates. EarthScience Reviews, 61:1-2, 43-104.

Douglas, J., 2011. Ground motion prediction equations 1964-2010, Rpt PEER 2011/102, Pacific Earthquake Engineering Research Center, UC Berkeley, April.

Douglas, J., and Mohais, R., 2009. Comparing predicted and observed ground motions from subduction earthquakes in the Lesser Antilles, J. Seism., 13, 577-587.

Douglas, J., Faccioli, E., Cotton, F. and Cauzzi, C., 2009. Selection of ground-motion prediction equations for GEM1. GEM Technical Report, GEM Foundation, Pavia, Italy.

Douglas J, Cotton, F., Di Alessandro, C., Boore, D.M., Abrahamson, N.A., and Akkar, S. 2012. Compilation and critical review of GMPEs for the GEM-PEER global GMPEs project, Proc. $15^{\text {th }}$ World Conf. Eqk. Eng., Lisbon, Portugal.

Electric Power Research Institute, 2006. Program on Technology Innovation: Truncation of the Lognormal Distribution and Value of the Standard Deviation for Ground Motion Models in the Central and Eastern United States., MD: 2006. 1014381, EPRI, Palo Alto, CA and U.S. Department of Energy, Germantown.

Electric Power Research Institute, 1993. Guidelines for determining design basis ground motions, Volumes 1-5, EPRI TR-102293, EPRI, Palo Alto, CA.

Ghasemi, H., Zare, M., Fukushima, Y. and Koketsu, K., 2009. An empirical spectral ground-motion model for Iran, J. Seism., 13, 499-515.

Ghasemi, H., Zare, M., and Fukushima, Y., 2008. Ranking of several ground-motion models forseismic hazard analysis in Iran, J. Geophy. \& Eng., 5, 301-310.

Goulet, C.A. and Stewart, J.P., 2009. Pitfalls of deterministic application of nonlinear site factors in probabilistic assessment of ground motions, Earthquake Spectra, 25:3, 541-555.

Gupta, I.D., 2010. Response spectral attenuation relations for in-slab earthquakes in Indo-Burmese subduction zone, Soil Dyn. and Eqk Eng, 30:5, 368-377.

Kaklamanos, J., Baise, L.G. and Boore, D.M., 2011. Estimating unknown input parameters when implementing the NGA ground-motion prediction equations in engineering practice, Earthquake Spectra 27, 1219-1235. 
Liao, Y. and Meneses. J., 2012. Comparison of ground motions from the $2010 \mathrm{Mw} 7.2 \mathrm{El}$ MayorCucapah earthquake with the next generation attenuation ground motion prediction equations, Bull Eqk. Eng., DOI 10.1007/s10518-012-9358-7.

Margaris, G. A., Mylonakis, G., Papaioannou, C. Klimis, N., Theodulidis, N., Savvaidis, A., Efthymiadou, V. and Stewart, J. P., 2010. The 8 June 2008 Mw6.4 Achaia-Elia, Greece Earthquake: Source Characteristics, Ground Motions, and Ground Failure, Earthquake Spectra, 26:399-422.

Nishimura, N., 2010. Conformity of the attenuation relationships in Japan with those by the NGAproject, Summaries of Technical Papers of Annual Meeting of Architectural Institute of Japan, (Hokuriku), September.

Pezeshk, S., Zandieh, A. and Tavakoli, B., 2011. Hybrid Empirical Ground-Motion Prediction Equations for Eastern North America Using NGA Models and Updated Seismological Parameters, Bull Seism. Soc. Am., 101:4, 1859-1870.

Scasserra, G., Stewart, J.P., Bazzurro, P., Lanzo, G. and Mollaioli, F., 2009. A comparison of NGA ground-motion prediction equations to Italian data, Bull Seism. Soc. Am., 99:5, 2961-2978.

Scherbaum, F., Delavaud, E. and Riggelsen, C., 2009. Model selection in seismic hazard analysis: An information-theoretic perspective, Bull Seism. Soc. Am., 99:6, 3234-3247.

Scherbaum, F., Cotton, F. and Smit, P., 2004. On the use of response spectral reference data for the selection and ranking of ground motion models for seismic hazard analysis in regions of moderate seismicity: The case of rock motion, Bull Seism. Soc. Am., 94:6, 2164-2185.

Seyhan, E and JP Stewart (2012). Site response in NEHRP Provisions and NGA models, in Geotechnical Engineering State of the Art and Practice:, Volume of Keynote Lectures from GeoCongress 2012, Oakland, CA, ASCE Geotechnical Special Publication No. 226, K. Rollins and D. Zekkos (eds.), 359-379.

Shoja-Taheri, J., Naserieh, S., and Ghofrani, H., 2010. A test of the applicability of NGA models to the strong ground motion data in the Iranian Plateau, J. Eqk. Eng., 14, 278-292.

Silva, W.J., Gregor, N. and Darragh, R., 2002. Development of regional hard rock attenuation relations for central and eastern North America, Tech. rept., Pacific Engineering and Analysis.

Somerville, P., Graves, R., Collins, N., Song, S.G., Ni, S. and Cummins, P., 2009. Source and ground motion models of Australian earthquakes, Proc. 2009 Annual Conf. Australian Eqk. Eng. Soc.

Stafford, P.J., Strasser, F.O. and Bommer, J.J., 2008. An evaluation of the applicability of the NGA models to ground motion prediction in the Euro-Mediterranean region, Bull Eqk. Eng., 6, 149177. 
Stewart, J.P., Midorikawa, S., Graves, R.W., Khodaverdi, K., Kishida, T., Miura, H., Bozorgnia, Y. and Campbell, K.W., 2013. Implications of Mw 9.0 Tohoku-oki Japan earthquake for ground motion scaling with source, path, and site parameters, Earthquake Spectra. Accepted. DOI: $10.1193 / 1.4000115$

Stewart, J.P. Douglas, J., Javanbarg, M.D., Di Alessandro, C., Bozorgnia, Y., Abrahamson, N.A., Boore, D.M., Campbell, K.W., Delavaud, E., Erdik, M., Stafford, P.J. (2013). Selection of a global set of ground motion prediction equations: Work undertaken as part of Task 3 of the GEMPEER Global GMPEs project, Report No. 2013/xx, Pacific Earthquake Engineering Research Center, Berkeley, CA.

Toro, G.R. (2002). Modification of the Toro et al. (1997) attenuation equations for large magnitudes and short distances, Technical Report, Risk Engineering.

Toro, G.R., Abrahamson, N.A. and Schneider, J.F., 1997. Model of strong ground motions from earthquake in central and eastern North America: Best estimates and uncertainties, Seism. Res. Ltrs., 68:1, 41-57.

Uchiyama, Y. and Midorikawa, S., 2011. A Study of the Applicability of NGA Models to Strike-Slip Earthquakes in Japan, Summaries of Technical Papers of Annual Meeting of Architectural Institute of Japan, Kanto, August.

Vilanova, S. P., Fonseca, J. F. B. D. and Oliveira, C. S., 2012. Ground-motion models for seismic hazard assessment in western Iberia: Constraints from instrumental data and intensity observations, Bull Seism. Soc. Am., 102:1, 169-184.

Zhao, J. X., Zhang, J, Asano, A., Ohno, Y., Oouchi, T., Takahashi,T., Ogawa, H., Irikura, K., Thio, H. K., Somerville, P. G. and Fukushima, 2006. Attenuation relations of strong ground motion in Japan using site classification based on predominant period, Bull Seism. Soc. Am, 96, 898-913. 